\title{
ESTAR LÁ, MAS TAMBÉM DO OUTRO LADO DA TELA: LIMITES E POSSIBILIDADES DA ETNOGRAFIA EM AMBIENTES VIRTUAIS E A PERCEPÇÃO DE BLOGUEIRAS DE MODA SOBRE DESIGN, PRODUTOS E SUSTENTABILIDADE
}

\author{
Nayara Chaves Ferreira Perpétuo \\ Universidade Federal do Maranhão \\ nayara_chaves@hotmail.com \\ Raquel Gomes Noronha \\ Universidade Federal do Maranhão \\ raquelnoronha79@gmail.com
}

Resumo: Diante de tantas possibilidades metodológicas não existem aquelas mais corretas ou mais importantes que outras. Ela é um ponto chave e sua escolha não deve ser aleatória. Aqui opta-se pela etnografia e esta escolha apoia-se em decisões que levam em consideração, além da sua pertinência, os limites e alcance para dar conta de responder à pergunta feita cientificamente. Neste caso: qual a percepção das blogueiras de São Luís-MA quanto à estratégia de design que otimiza a vida de produtos de moda? O usuário tem uma experiência em seu cotidiano com os produtos que o designer não tem. Por isso, no intuito de entender, em termos qualitativos, se um sistema possui problemas relacionados ao fomento do consumo responsável e sustentável é preciso questionar se o consumidor percebe e dá continuidade às estratégias de design no uso. Esse artigo dedica-se ao delineamento desta metodologia de modo a evidenciar suas implicações para comparar discursos e práticas de um grupo de consumidores que também se projetam como formadoras de opinião e podem influenciar nas práticas de consumo de seus seguidores.

Palavras-chave: design; metodologia; etnografia.

Abstract: With so many methodological possibilities there are those more correct or more important than others. It is a key point and your choice should not be random. Here the option is to ethnography and this choice relies on decisions that take into account, in addition to its relevance, the limits and scope to account to answer the question posed scientifically. In this case, what is the perception of bloggers São Luis-MA on the design strategy that optimizes the life of fashion products? The user has an experience in their daily lives with the products that the designer does not have. Therefore, in order to understand, in qualitative terms, if a system has problems related to the promotion of responsible and sustainable consumption is necessary to question if the consumer perceives and continues to design strategies in use. This article is dedicated to the design of this methodology in order to identify their implications for comparing 
discourses and practices of a group of consumers who also design as opinion-forming and can influence the consumption practices of his followers.

Keywords: design; methodology; ethnography.

\section{INTRODUÇÃO}

Este artigo é resultado de parte de uma pesquisa em andamento que culminará numa dissertação de mestrado em Design no Programa de Pós graduação em Design Universidade Federal do Maranhão - UFMA e desenvolvida a partir da integração no Núcleo de Pesquisas em Imagem, Design e Antropologia - NIDA. Desde a delimitação do seu tema, surgiu uma inquietação frente ao discurso de total incompatibilidade entre moda e sustentabilidade.

A sustentabilidade é uma das maiores críticas já enfrentadas pela moda, porque a desafia como um todo, desde o uso de materiais e processamentos até os modelos econômicos e sistemas de crenças e valores. $O$ discurso da incompatibilidade normalmente figura a partir de pré-noções que costumam desconsiderar o papel estratégico do design na busca de soluções para os desafios apresentados no cenário atual.

Parte-se do pressuposto que os produtos da moda estão longe de ser uma criação artística que escapa à razão, ou a mera expressão da futilidade alheia. Eles são uma construção racionalizada e por isso, os problemas por eles gerados devem ser administrados também racionalmente: deve-se criar e experimentar novas possibilidades.

O design, enquanto área de conhecimento, possui ferramentas capazes de contribuir para o desenvolvimento de práticas e estilos de vida sustentáveis com o aprofundamento de suas propostas na constante avaliação comparada das implicações ambientais, nas diferentes soluções técnica, econômica e socialmente aceitáveis (MANZINI; VEZZOLI, 2008).

Na concepção do produto de moda a adoção de práticas sustentáveis tem se tornado possível e muito é feito para inovar e melhorar as credenciais de sustentabilidade nos produtos. São possibilidades reais as estratégias de minimização de recursos, escolha de recursos e processos de baixo impacto ambiental, otimização da vida de produtos, extensão da vida dos materiais e facilitar a desmontagem.

Dentre as diversas atuações dos designers para alterar da dinâmica dos produtos, chama a atenção a estratégia para otimização da vida de produtos proposta pelos autores Manzini e Vezzoli (2008) e apontada didaticamente na ferramenta Eco.cathedra desenvolvida pelo Politécnico de Milano - POLIMI, como aquela que melhor atente no combate ao descarte motivado pela obsolescência simbólica e cultural dos produtos de moda.

As oito ações propostas por essa estratégia (projetar a duração adequada, projetar a fidelidade, facilitar a atualização e adaptabilidade, facilitar a manutenção, facilitar o reuso, facilitar o reparo, facilitar a re-fabricação e intensificar o uso), podem ser aplicáveis em produtos de moda e tem repercussão associada à fase de uso do produto, logo, envolvendo diretamente o consumidor. 
Uma percepção comum na indústria da moda segundo Salcedo (2014) é de que uma vez nas mãos do consumidor, o produto deixa de ser uma responsabilidade do designer. Inúmeros problemas originam-se deste distanciamento. Ao transpor a linearidade para uma relação cíclica, como são propostos os pensamentos sustentáveis, começamos a repensar as mudanças dos paradigmas firmados até então. Percebemos aproximadas, assim, a moda e a sustentabilidade.

A moda por si só é um fenômeno sociológico, já que não existe de outra forma, a não ser coletivamente. Seu sentido está na relação estabelecida entre criadores, formadores de opinião e consumidores; logo, nas vivências, nas representações e naquilo que orienta as percepções das pessoas em relação às roupas.

Parte-se do pressuposto de que "a mídia constitui uma verdadeira interface, ou um filtro entre os criadores de moda e os consumidores finais que compram as roupas" (GODART, 2010, p. 124). Logo, o consumo desses produtos e a manutenção de seu ciclo são amplamente fomentados pelos meios de comunicação, dentre os quais recentemente ganham destaque os blogs. Por eles, consumidores que atuam como blogueiros, são caracterizados também como formadores de opiniões.

Descrever e analisar a percepção das blogueiras de São Luís-MA quanto às estratégias de design que otimizam o uso de produtos de moda é possível por meio da etnografia. Neste artigo faz-se uma reflexão sobre a prática etnográfica conforme Geertz (1989): estabelecendo relações, selecionando informantes, transcrevendo textos, mapeando campos, mantendo diários etc.

Questões que advém do consumo, como a efemeridade e a permanência dos artefatos, valorizando os seus aspectos simbólicos e a construção da identidade a partir do vestuário; o papel da pesquisadora, que presente em campo, é ator que influencia a percepção dos sujeitos de pesquisa, como enfatizado nas abordagens reflexivas da pesquisa etnográfica, serão importantes para esta pesquisa.

A discussão proposta inicia explicitando-se as conexões possíveis que dão sentido sociológico ao problema estudado e torna-se possível contextualizar o porquê da escolha da abordagem, sua aplicação e adaptações necessárias. Em um segundo momento apresenta-se análises dos dados coletados em campo como resultado da metodologia adotada e conclui-se evidenciando a experiência singular do designer, como pesquisador, experimentando no momento em que o produto está sob domínio de terceiros, as falhas e acertos do projeto.

\section{DESCOBRINDO O CAMPO DE PESQUISA “ESTANDO LÁ", ESTRANHANDO O FAMILIAR E DISCIPLINANDO O OLHAR E O OUVIR}

A existência de uma abordagem que relata todos os aspectos em totalidade biológico, social, cultural e psicológico - de um contexto de estudo, principalmente compreendendo-os de maneira interdependente faz com que essa pesquisa não seja percebida de outro modo e justifica-se a escolha pela etnografia.

$\mathrm{Na}$ pesquisa etnográfica é o trabalho de campo que proporciona um contato intenso e prolongado com um grupo em estudo e torna possível ao pesquisador descobrir como um sistema de significados culturais está organizado, como se desenvolveu e como influencia o comportamento grupal.

O fazer etnográfico, na contemporaneidade, estreita as fronteiras entre o espaço do pesquisador e o do nativo. Se antes essas distâncias eram enormes, hoje, ao realizar etnografias de nossos pares, a proximidade física se intensifica - e por isso, a 
necessidade de problematização da questão do familiarizar-se e do estranhamento, torna-se ainda mais importante (CLIFFORD, 1997). O processo de distanciamento e estranhamento de práticas tão corriqueiras para nós, como vestir e acessar e ler um blog, tornam-se problematizadas neste estudo.

Foi eleito como universo empírico tanto o cotidiano das blogueiras quanto o ambiente virtual dos blogs, já que são nesses espaços que elas interagem com os produtos e estabelecem contatos, propagando informações e opiniões.

A prática etnográfica ocorreu simultaneamente nos dois campos escolhidos. Contudo, uma vez que os blogs figuram como um campo empírico on-line fez-se necessárias adaptações da etnografia ao mundo virtual e suas implicações. Ela, tradicionalmente composta pela observação empírica in loco e entrevistas, neste caso, altera seu escopo analítico para os textos e imagens disponibilizados no ambiente virtual.

O papel do pesquisador na rede consiste em observar um determinado grupo social, intervindo o mínimo possível nas suas práticas cotidianas. Este comportamento possível no ciberespaço é denominado lurking traduzido como "ficar à espreita" (BRAGA, 2006). Em nosso caso, nenhuma interação é realizada com os sujeitos da pesquisa virtualmente, a etnografia nesse meio dá-se apenas a partir dos dados publicados na rede espontaneamente e disponíveis para acesso irrestrito.

Para mergulhar em uma pesquisa empírica no campo real seguiu-se as três etapas apontadas pelo antropólogo Roberto da Matta, sendo elas: "teóricointelectual", "período prático" e "pessoal ou existencial" (DA MATTA, 1978, p. 24). A primeira ocorre antes do contato com os sujeitos da pesquisa, nele dedica-se a uma imersão teórica para um conhecimento abstrato do que posteriormente será confrontado com a realidade. A segunda diz respeito ao planejamento para o estar em campo. Já a última é aquela onde é finalmente estabelecido o contato com os informantes da pesquisa, nela o pesquisador projeta-se para realidade de sua pesquisa e pode, inserido no campo, compreender de forma mais efetiva como funcionam as dinâmicas do objeto estudado.

A primeira etapa é fundamental para garantir competência ao pesquisador no campo e a continuidade das etapas seguintes. Nesse momento foi feito um levantamento teórico dos conceitos de sustentabilidade, definição de produto de moda a partir da diferenciação entre moda e roupa e feito um levantamento das práticas de design sustentáveis aplicadas ao vestuário de moda que podem ser estabelecidas na relação consumidor e produto durante a fase de uso (PERPÉTUO; NORONHA, 2016).

Foi-se além de uma revisão bibliográfica e do levantamento do estado da arte do tema estudado. Buscou-se uma formação capaz de garantir ser visto com bons olhos pelos sujeitos da pesquisa, já que estes a seu modo também pesquisam e são capazes de perceber ignorância e ingenuidade em pequenos deslizes do pesquisador.

$\mathrm{Na}$ cidade de São Luís - MA, como em outros locais, os blogs deixaram a concepção de diários online e passaram a ser percebidos pelo mercado como excelente ferramenta de divulgação de marcas. A plataforma de blogs Top Trends Slz é um exemplo dessa realidade e dela fazem parte dez blogs conduzidos por mulheres com perfis diferenciados. Essa iniciativa possibilita, como organização jurídica, o reforço da atividade de blogueira também como um ofício. Três deles foram selecionados como campo empírico dessa pesquisa e as blogueiras responsáveis por 
eles tornam-se sujeitos da pesquisa ou informantes: Hérica Soares (Blog Pensando Estilo), Flávia Batista (Blog Digo por aí) e Mirian Soares (Blog A moda na Mira).

Ao conhecê-las são considerados como aspecto de importante reflexão a representação e a apresentação dos atores sociais através das mídias. Erwing Goffman afirma que dependendo do contexto, os atores sociais representam papéis determinados, querendo transmitir aspectos específicos sobre seus discursos e práticas (GOFFMAN, 2011), utilizando-se da metáfora teatral: atores, palco, encenação. Com isso é lícito cogitarmos, como problematização do campo empírico escolhido que, para passarem determinado tipo de ideia ou visão de mundo, as blogueiras assumem determinados discursos que são traduzidos no blog por meio de imagens e palavras que têm a função de construir o estilo de cada uma delas.

A influência exercida pelas blogueiras não está nelas enquanto uma categoria de indivíduos que possuem certa competência no assunto, mas na rede de sociabilidade à qual cada uma delas pertence. Por isso, é em seu cotidiano que se encontram os contatos sociais responsáveis por fazer crescer a passos largos a quantidade de seguidores e mensurar sua difusão. O seu trabalho que vai além de escrever notícias para o ambiente virtual, sua principal qualidade é servir segundo o sociólogo Guillaume Erner (2015) como nó de informação, logo colocam em contato indivíduos uns com os outros. Isso é possível por participarem de lançamentos de coleções, inaugurações de lojas, serem entrevistadas, participarem e realizarem eventos, manterem mídias sociais atualizadas constantemente, além de serem a qualquer momento identificadas e abordadas nas ruas.

Inserir-se nesse espaço inicialmente como seguidora ativa de suas mídias sociais e blogs foi um primeiro passo para estreitar a relação com as informantes e fez parte do planejamento que define a segunda etapa do trabalho de campo. Passou-se a acompanhar diariamente suas rotinas, principalmente por meio do aplicativo Snapchat. Por serem pessoas públicas e trabalharem com a sua imagem esse acesso não impõe nenhuma restrição no meio virtual. Dessa forma, obteve-se informações privilegiadas e por que não dizer até íntimas. Com a acessibilidade, garantida pela exposição on-line e espontânea das blogueiras, foram mapeados os lugares que frequentam constantemente, preferências musicais e os eventos que participam e promovem.

A terceira e última fase da pesquisa empírica dá-se através de uma participação mais ativa e interativa com as informantes. Seu início foi possível em um dos eventos realizados por elas. Contudo, é importante frisar que a etnografia também continua ocorrendo no campo virtual, pois este é suporte para o novo campo a ser explorado.

A estratégia de aproximação utilizada com planejamento é pautada em Bourdieu (1997) para o estabelecimento de uma relação entre pesquisador e pesquisado. O mesmo autor também sinaliza que o sucesso de uma pesquisa perpassa por uma boa comunicação que possibilita uma negociação como parte constitutiva.

Uma vez tendo sido feita a aproximação gradual é feita essa negociação com as informantes para a efetiva observação participante, sabendo que a finalidade da pesquisa pelo pesquisador e pelo pesquisado são distintas. Desse modo, mantém-se o controle dos aspectos e interesse dos envolvidos.

Para as blogueiras, participar de uma pesquisa científica é uma forma de valorização de seu trabalho e também um sinônimo de prestígio. Contudo, mesmo sem nenhum interesse direto, suas participações na pesquisa são voluntárias pelo 
simples fato de gostarem de trabalhar com moda e quererem ajudar.

Ao observar é o contexto que define o que será compreendido, captando suas explicações e interpretações. Gradualmente a observação vai se sistematizando, com o uso de instrumentos para coleta de dados ou fenômenos observados, tais como quadros, anotações, fotografia, dispositivos eletrônicos.

Para isso, a disciplina do olhar e ouvir, conforme sugere Roberto Cardoso Oliveira (2000), constituem a percepção da realidade focalizada na pesquisa empírica e fazem parte de uma observação participante. Deles depende a escrita do texto, ao trazer os fatos observados para o plano do discurso, marcado fortemente pela atitude relativista.

Uma importante ferramenta utilizada, sem dúvidas, é o caderno de campo que funciona mais que como um registro de informações. Seu uso dá-se como um instrumento pré-reflexivo, uma vez que a observação ancorada em um conjunto de referenciais teóricos oportunizará uma descrição fundamentada, logo uma pré-análise (DEWALT, DEWALT, WAYLAND, 1993).

Por se tratar de uma pesquisa de observação na vida real, registram-se os dados à medida que ocorrem, reduzindo as tendências seletivas e deturpações. Por ocorrer no cotidiano, podem haver interferências, contudo os objetivos da pesquisa devem manter-se claros norteando a prática do pesquisador.

Após o registro de tudo de maneira descritiva, acreditando que tudo pode ser importante, começamos a enxergar certa ordem nas coisas, neste momento informações específicas se transformam em material significativo para a pesquisa. $\mathrm{Na}$ sequência, pondo em ordem e tornando acessível e compreensível através da escrita o que foi coletado em campo a quem não participou dele, espera-se que seja feita a união de teoria e prática.

Em atenção ao problema da pesquisa define-se quanto aos seus procedimentos de análise de dados natureza qualitativa. A análise será dada a partir de uma sequência de atividades, sendo elas: redução, categorização e interpretação dos dados para enfim culminar na redação do relatório. Esta, por sua vez, precisa ser feita de forma rigorosa, conforme Sardan (2008).

Do campo empírico on-line são analisadas especialmente as publicações com a tag "look do dia", pois estas postagens não são classificadas como publicidade e o texto das informantes soa como uma opinião fidedigna e sempre vem acompanhadas de fotos delas usando os produtos. Para possibilitar a interpretação de textos e imagens como discursos, recorre-se às metodologias de interpretação de imagens. Sarah Pink (2006) alerta que os significados das fotografias são arbitrários e subjetivos: eles dependem de quem está olhando as imagens. Desta forma, a interpretação de imagens, não é apenas uma ferramenta para a construção do conhecimento, mas uma forma de se entender a reflexividade e a experiência etnográfica por meio de materiais visuais. Ainda conforme Pink (2006), as imagens não apenas auxiliam no processo de construção de conhecimento, mas propiciam a produção de conhecimentos diferentes dos que as palavras provocam.

Uma vez descrita a metodologia, apresenta-se a seguir os resultados de sua aplicação de tal forma que fique claramente evidenciada sua abrangência. 


\section{PERCEPÇÕES DAS BLOGUEIRAS DE MODA SOBRE A ESTRATÉGIA DE DESIGN PARA OTIMIZAÇÃO DE PRODUTOS}

O processo etnográfico permite uma visão holística do objeto estudado, por isso algumas descobertas feitas em campo apresentam relevância significativa que vão além de respostas aos objetivos específicos estabelecidos. Os resultados não são meramente apresentados, mas contextualizados tornando o processo interpretativo muito mais consistente.

Em campo evidenciou-se a percepção de seis das oito ações possíveis pela estratégia de otimização da vida de produtos encontrada na ferramenta Eco.cathedra, sendo elas: projetar a duração adequada, projetar a fidelidade, facilitar a atualização e adaptabilidade, facilitar a manutenção, facilitar o reparo e intensificar o uso. As ações de facilitar o reuso e facilitar a re-fabricação não são percebidas.

Nos subitens que seguem apresentam-se as reflexões sobre as representações e práticas das blogueiras e sobre suas relações com as roupas. Estrutura-se a análise por ação a partir das situações e narrativas experimentadas em campo.

\subsection{O design para projetar a duração adequada}

A ação de design para projetar a duração adequada em um contexto de produtos de moda está associada as concepções de fast fashion e slow fashion. Estas caracterizam-se pela velocidade com que o processo de criação, produção, distribuição e venda dos produtos ocorre. Por consequência dessas práticas a forma de consumo e o descarte também se distinguem em mais rápido ou mais lento.

No primeiro caso a rapidez é valorizada com objetivo de ofertar novidades constantes ao consumidor no momento em que as tendências de consumo estão no auge de sua força, logo é mais adequado a consumidores que acompanham as tendências de moda.

Essa velocidade exige uma logística específica para abastecer os pontos de venda (chegando até um ritmo quinzenal); diversificação de marcas; conhecimento do mercado; investimentos em comunicação; e política comercial de segmentação de consumidores. Esse contexto também acarreta em alguns agravantes, tais como: questões centradas no relacionamento com subfornecedores que integram a cadeia produtiva; diminuição da qualidade percebida; barateamento dos custos das mercadorias; maior volume de produção; aumento do consumo, compras impulsivas e descarte inconsequente do vestuário.

Já o segundo caso - slow fashion - é marcado pela conjunção do prazer em criar, inventar e inovar com o prazer em consumir. Nele há uma diminuição da rapidez e da frequência com a qual se consome paralelamente à produção em pequena escala, uso de técnicas tradicionais como recursos de confecção, materiais e mercados locais, ou seja, um modo de produção e consumo mais responsável e menos impulsivo. Isso só é possível informando ao consumidor a procedência dos produtos envolvendo-o e, por isso, os impactos até seu descarte passam a ser considerados pelo consumidor no uso.

Tais conceitos são conhecidos e aplicados pelas blogueiras e só foi possível reconhecer a diferença entre o que é proveniente de fast e o que é proveniente de slow fashion no contato direto com o guarda-roupa de cada uma, tendo acesso às peças. No processo de imersão no cotidiano foi feita a identificação do tipo de produto que é consumido e como se dá a relação de cada uma delas com as roupas. 
Por trabalharem com moda, as blogueiras conhecem com profundidade as tendências. Estas por sua vez costumam estar intimamente associadas à concepção de fast fashion, pois remetem à novidade e mudança mais rápida. Portanto, reitera-se a argumentação de Lipovetsky (2009) e aponta-se o uso dos produtos de moda em função do gosto pela novidade.

Elas não acompanham o processo de desenvolvimento do produto e seu contato se dá como o da maioria dos consumidores: quando o produto é lançado no mercado. É nesse momento, marcado pela presença intensa dos recursos da comunicação, que seu papel como formadora de opinião é mais efetivo. Embora contribuam para a promoção e propagação dos produtos, elas também se sentem envolvidas pelo contexto. Hérica assume ser impossível não se sentir influenciada pelo fetichismo das marcas. O reflexo dessa influência em todos os eventos de lançamento acompanhados foram as sacolas as acompanhavam na saída das lojas. Os produtos adquiridos são provenientes de vouchers, presentes e/ou compras pessoais.

No campo da moda, o estilo é a expressão da individualidade que ultrapassa mudanças sazonais, é duradouro e reflete características pessoais do indivíduo (GODART, 2010). A questão da projeção da imagem pautada em um estilo é valorizada e administrada por elas de maneira muito consciente.

Esse pré-requisito sobrepõe-se às tendências no momento das escolhas. Logo, as práticas de design numa concepção de fast fashion aliada diretamente às tendências não é garantia infalível de uso. Elas só são usadas se também forem incorporadas ao estilo compondo harmoniosamente uma imagem consolidada e coerente com a individualidade de cada uma. Como as tendências seguem a dinâmica de ciclos de moda curtos, é esperado que as peças nesse padrão sejam usadas enquanto estão em voga, mas esta não é uma regra que se atribui ao caso dos sujeitos dessa pesquisa.

Mirian é quem apresenta uma singularidade que a enquadra como aquela que pratica mais ativamente o slow fashion. Ela possui envolvimento profundo com a marca Antix, caracterizada por um estilo autêntico que mistura romance, feminilidade e delicadeza em cada uma das suas peças. As estampas exclusivas e o apelo lúdico fizeram com que a marca ganhasse fãs apaixonadas que vão muito além de consumidoras.

Encontrei com Mirian durante um trabalho para a equipe de marketing de um Shopping da cidade para uma campanha de liquidação. Durante o encontro, ela acabou comentando sua relação com a marca e a comparou à sensação de colecionar papel de carta. Estes são produtos que ela não compra por tendências, mas por envolvimento. Cada coleção conta uma história, as estampas são envolventes e ela se sente representada. Seu guarda-roupas possui muitas peças de várias coleções que a acompanha em diversas ocasiões, desde o trabalho até um evento social que exija um traje mais formal.

Quando tive a oportunidade de conhecer os produtos da Antix de Mirian, ela fez questão de apresentar do mais antigo ao mais recente. Ela comentou que já descartou vestidos dessa marca, mas esse processo é criterioso. Ela se desfaz dos produtos pela venda direcionada a outras consumidoras de Antix em comunidades específicas nas mídias sociais. $O$ descarte quando ocorre por troca entre consumidoras da marca é uma estratégia das usuárias para o prolongamento da vida útil do produto, já que ao ser adquirido por outro com similar envolvimento, este terá maior 
probabilidade de otimizá-lo, diminuindo o descarte final.

\subsection{Projetar a fidelidade e Facilitar a atualização e adaptabilidade}

Nos conceitos de neutro e básico encontram-se prerrogativas para a associação a outras ações de design: projetar a fidelidade e facilitar a atualização e adaptabilidade.

Os produtos básicos e neutros refletem a ação de projetar a fidelidade através da minimização do número de partes componentes e simplificação dos produtos. Nos básicos as modelagens normalmente são limpas e não possuem aviamentos como detalhes desnecessários, já as neutras normalmente são marcadas pela sobriedade nas cores. Produtos com essas características possibilitam composições de looks variados e fazem com que a usuária recorra a peça mais vezes, logo ela torna-se fiel ao produto. Essa estratégia também ganha corpo pelo contexto social vivido que coloca a praticidade como um diferencial valorizado.

No blog Hérica ilustra bem isso ao descrever uma foto usando uma saia bege e uma blusa offwhite: "imagina a facilidade que vai ser combinar a blusa e a saia desse conjunto com outras peças! Eis mais uma vez a grande vantagem de investir em cores neutras, você fica com muito mais possibilidades de usos e combinações diferentes" (SOARES, 2015).

Peças simplificadas ao cumprirem com a prerrogativa a versatilidade são reconhecidas positivamente pelas blogueiras. Dada à essa característica é oportunizado ao usuário a possibilidade de estabelecer um número maior de combinações em um exercício de sua individualidade que entra em consonância com o uso simbólico estabelecido pela moda, daquilo que remete ao novo e não ao que já foi experimentado.

O apreço pelo novo facilita a aceitação das ações de design para facilitar a atualização e adaptabilidade. Flávia em suas postagens faz uso da percepção dessa ação para produzir conteúdo para seus leitores:

\footnotetext{
hoje vou começar uma tag nova aqui no blog: 1 peça, 3 looks. Nela, vou escolher uma peça do meu guarda-roupa, que julgo ser bem dinâmica e que me permite criar várias opções de looks com ela (...) quero pelo menos uma vez por mês trazê-la aqui para dar ideias de como usar e abusar de peças que a gente tem no guarda-roupa. Uma das coisas mais bacanas que acho é termos consciência do que a gente tem e como podemos aproveitar tudo ao máximo. Afinal, roupa, acessórios, etc, estão com preços tão altos, que não dá pra comprar coisas para serem descartáveis. Vocês concordam? (BATISTA, 2016).
}

Também faz parte da ação de design para facilitar a atualização e adaptabilidade o desenvolvimento de produtos multifuncionais, para adaptação em respeito à evolução física e cultural dos indivíduos.

Quem usa o lenço enquanto peça multifuncional de maneira muito consciente é Hérica. No blog ela publica várias fotos usando o produto de diversas maneiras. Ao usá-lo como uma blusa frente única apresenta como faz a adequação do produto para essa função na postagem: 
pontas que se juntam e dê um nó firme, passe o colar, pendure o colar no pescoço (deixe o nó escondido na parte de dentro), pegue as pontas laterais e amarre atrás. Se você não quiser usar com as costas nuas é só acrescentar um casaquinho ou um blazer. Um casaquinho ou cardigã deixa o looks mais despojado e com o blazer fica mais elegante (SOARES, 2015).

Ela também usa o lenço como acessório conferindo possibilidades diversas aos looks, mais uma vez garantindo o requisito da novidade em cada composição, mesmo que este seja formado pelas mesmas peças. Esse recurso quando aplicado para facilitar a atualização e adaptabilidade contribui para a otimização das peças que se revigoram em cada possibilidade explorada, logo os produtos demoram muito mais para tornarem-se obsoletos por aspectos meramente simbólicos e sociais.

\subsection{Facilitar a manutenção}

Hérica terceiriza os cuidados com a manutenção das peças, mas afirma que sempre orienta as pessoas que trabalham para ela na lavagem adequada das peças. Além da questão estética ela também atribui a durabilidade dos produtos à manutenção adequada. Afirma que é muito difícil que suas roupas se desgastem no uso, logo é o momento da manutenção que elas mais depreciam, principalmente na lavagem.

Diferente dela, é Mirian quem lava suas roupas por assumir que tem ciúmes de seus produtos. Em um desses momentos verificou-se que ela faz a separação dos produtos para a lavagem de acordo com o tecido, sendo lavagem à mão apenas as peças mais delicadas. $O$ tipo de lavagem não é feito pela recomendação das etiquetas. Estes instrumentos informativos para a manutenção que acompanham as peças quer seja por meio de etiquetas internas fixadas os externas removíveis são percebidos negativamente, pois elas não consideram questões relacionadas ao conforto.

\subsection{Facilitar o reparo}

A ação de facilitar o reparo foi percebida pela Mirian como uma grande vantagem para a aquisição de um produto que ela vinha desejando: um colete longo. Do provador da loja ela compartilhou nas redes socais que a peça estava com desconto em decorrência da ausência de um dos botões, mas que havia um botão reserva que acompanhava o produto.

Pelo blog acompanhou-se a primeira vez que Mirian usou seu colete em um evento comemorativo para o dia da mulher realizado em um restaurante da cidade. Alguns dias depois em uma visita a sua residência surgiu a oportunidade de perguntar sobre a peça. No contato direto com o colete notou-se que ainda estava sem o botão e ela confirmou que tinha usado assim mesmo no evento. Portanto, a partir deste relato observa-se que embora a estratégia seja percebida na ocasião da compra não foi executada com sucesso.

\subsection{Intensificar o uso}

A ação de design para intensificar o uso das peças vale-se de produtos-serviços. Exemplos dessa ação em produtos de moda são os aluguéis de trajes de festa. Flávia compartilhou no blog o momento da escolha de seu vestido de noiva: 
Estava decidida a alugar um sereia lindo, meio off white, com aplicações e paetês bem pequeninhos embaixo de umas pluminhas bem minúsculas. Era um mimo! E super chique! Até o costureiro trazer o "meu vestido". Eles ainda estavam costurando e levaram para eu ver, porque eu queria muito um primeiro aluguel. E como era só para dezembro, dava tempo deles terminarem... E foi com ele que fiquei (BATISTA, 2014).

O relato descreve claramente a constatação de Vezolli et al (2014) para justificar que no contexto do produto de moda, a roupa é menos adequada para alugar por longo prazo, logo atendia perfeitamente a situação de um casamento onde a peça não seria repetida em outras ocasiões. Ainda que haja a percepção da ação para intensificar o uso pode-se identificar também que neste caso trata-se de um vestido de primeiro aluguel, ou seja, o carácter inédito e a valorização do novo se mantém.

\section{CONCLUSÃO}

A pesquisa em Design tendo o designer como pesquisador experimentando, pela etnografia, o contato direto com os sujeitos para quem desenvolve produtos, nos faz perceber aproximados os atores diretamente envolvidos com a questão do consumo e da sustentabilidade. Logo, uma oportunidade singular de evidenciar, no momento em que o produto está sob domínio de terceiros, as falhas e acertos do projeto.

Através da comparação dos discursos com as práticas, confronta-se as teorias acadêmicas que legitimam os conceitos com a aplicabilidade destes no dia-dia. Podese dizer que cada blogueira, de maneira consciente ou não, percebe e/ou dá continuidade às ações de design para otimizar a vida de produtos.

A etnografia no campo virtual oportunizou ao campo real facilidade de acesso, embasamento e melhores condições de interação. Também tornou possível confrontar informações e esclarecer conceitos. Quando ocorriam em paralelo também proporcionou a percepção da interferência do pesquisador no contexto pesquisado, como por exemplo as pautas que remetem a conversas específicas da pesquisa.

A pesquisa, oportunizada por uma metodologia que propicia a imersão no cotidiano dos usuários dos produtos, garante uma contribuição para o fortalecimento da produção de conhecimento científico em Design, especialmente no de moda. Além de reforçar o papel desse profissional como ator estratégico tanto para a competitividade das organizações nos desafios oriundos da globalização dos mercados, quanto para a produção e crítica da cultura material nas sociedades contemporâneas.

\section{REFERÊNCIAS}

BATISTA, Flávia. Meu vestido de Noiva. São Luís: Digo por aí, 2014. Disponível na internet por http em: <http://www.digoporai.com/2014/01/meu-vestido-de-noiva/>. Acesso em 05 jan. 2016.

1 peça, 3 looks: Pantacourt. São Luís: Digo por aí, 2016. Disponível na internet por http em: <http://www.digoporai.com/2016/03/1-peca-3-lookspantacourt/>. Acesso em 08 mar. 2016.

BOURDIEU, Pierre. Compreender. In: A miséria do mundo. Petrópolis: Vozes, 5 a Ed., 1997. p. 693-732. 
BRAGA, Adriana. Técnica etnográfica aplicada à comunicação online: uma discussão metodológica. UNIrevista. Vol. 1 no 03, julho 2006.

CARDOSO de OLIVEIRA, Roberto. O trabalho do antropólogo: olhar, ouvir, escrever. In: O Trabalho do Antropólogo. Brasília/São Paulo: Paralelo 15/Ed. UNESP, 2000, p. 17-35.

CLIFFORD, James. Routes: travel and translation in the twentieth century. Cambridge: Harvard University Press, 1997.

DAMATTA, Roberto. O ofício do etnólogo, ou como ter -Anthropological Blues. In: NUNES, E. O. A aventura sociológica: objetividade, paixão, improviso e método na pesquisa social. Rio de Janeiro: Zahar Editores, 1978. p. $23-35$.

DEWALT, Kathleen M., DEWALT, Billie R. e WAYLAND, Coral B. Participant observation. In: BERNARD, H. Russel. Handbook of methods in cultural antropology. New York: Oxford, 1993, p. 259-299.

ERNER, Guillaume. Sociologia das tendências. 1 ed. São Paulo: Gustavo Gili, 2015. GEERTZ, Clifford. A interpretação das culturas. Rio de Janeiro: LTC, 1989.

GODART, Frédéric. Sociologia da moda. São Paulo: Editora Senac São Paulo, 2010. GOFFMAN, Erving. A representação do Eu na vida Cotidiana. 18. ed., Petrópolis: Vozes, 2011.

LIPOVETSKY, Gilles. O império do efêmero: a moda e o seu destino nas sociedades modernas. São Paulo: Cia. das Letras, 2009.

MANZINI, EZio; VEZZOLI, Carlo. O desenvolvimento de produtos sustentáveis. Os requisitos ambientais dos produtos industriais. São Paulo: Editora da Universidade de São Paulo, 2008.

OLIVIER DE SARDAN, Jean-Pierre. La riguer du qualitatif: les contraentes empiriques de linterprétation sócio-anthropologique. Louvain-la-Neuve: Academia Bruylant, 2008.

PERPÉTUO, Nayara Chaves Ferreira; NORONHA, Raquel Gomes. Intervenções do design para aumentar a vida útil dos produtos de moda na fase de uso. In: Anais do 5o

Simpósio Brasileiro de Design Sustentável [=Blucher Design Proceedings, v.2, n.5]. São Paulo: Blucher, 2016. p. 445-455.

PINK, Sarah. The future of visual anthopology. London: Routledge, 2006.

SALCEDO, Elena. Moda ética para um futuro sustentável. São Paulo: GGmoda, 2024.

SOARES, Hérica. Get the look - Blusa de lenço e colar de pérola. São Luís: Pensando Estilo, 2015. Disponível na internet por http em: < http://pensandoestilo.com/index.php/2015/12/19/get-the-look-blusa-lenco-colarperola/>. Acesso em 19 dez. 2015.

Get the look - Branco e bege. São Luís: Pensando Estilo, 2015. Disponível na internet por http em: <http://pensandoestilo.com/index.php/2015/12/28/11333/>. Acesso em 28 dez. 2015.

VEZZOLI, Carlo et al. Product-Service System Design for Sustainability. Sheffield, UK: Greenleaf Publishing, 2014. 